\title{
The Prevalence of Brain and Neck Injuries in Patients with Maxillofacial Fractures in Teaching Hospitals of Rasht in 2016
}

\author{
Ali Khalighi Sigaroudi', Seyed Mohammad Talebzadeh¹, Babak Alijani², Safa Motevasseli \\ Saied Dashtyari' ${ }^{1}$ Zeinab Davoudmanesh ${ }^{3,4}$, Mahsa Shariati ${ }^{5}$
}

${ }^{1}$ Department of Oral and Maxillofacial Surgery, Dental Sciences Research Center, Faculty of Dentistry, Guilan University of Medical Sciences, Rasht, Iran

${ }^{2}$ Department of Neurosurgery, Faculty of Medicine, University of Medical Sciences, Rasht, Iran

${ }^{3}$ Craniomaxillofacial Research Center, Tehran University of Medical Sciences, Tehran, Iran

${ }^{4}$ Craniomaxillofacial Research Center, Islamic Azad University, Tehran, Iran

${ }^{5}$ Department of Orthodontics and Dentofacial Orthopaedics, Tehran University of Medical Sciences,

Shariati Hospital, Tehran, Iran

Email:Dr.davoudmanesh@gmail.com

How to cite this paper: Sigaroudi, A.K., Talebzadeh, S.M., Alijani, B., Motevasseli, S., Dashtyari, S., Davoudmanesh, Z. and Shariati, M. (2017) The Prevalence of Brain and Neck Injuries in Patients with Maxillofacial Fractures in Teaching Hospitals of Rasht in 2016. International Journal of Clinical Medicine, 8, 631-637.

https://doi.org/10.4236/ijcm.2017.811059

Received: May 31, 2017

Accepted: November 27, 2017

Published: November 30, 2017

Copyright $\odot 2017$ by authors and Scientific Research Publishing Inc. This work is licensed under the Creative Commons Attribution International License (CC BY 4.0).

http://creativecommons.org/licenses/by/4.0/

\section{(c) (i) Open Access}

\begin{abstract}
This study aimed to determine the prevalence of brain and neck injuries in patients with maxillofacial fractures in teaching hospitals of the city of Rasht in 2016. This is an analytical retrospective study. Some 361 patients of the training centers of Rasht who had been diagnosed with maxillofacial fractures entered the study, 286 of which were male and 75 were female. Information was collected through questionnaires and patients' records who admitted to Emergency Department of Poursina and Velayat Hospitals with maxillofacial fractures. The patients were examined to see whether they have brain and cervical spine injuries. The diagnosis of the fracture and brain and neck injuries had been separately written by the related doctors on the records of the patients based on clinical examination and Plain radiography and CT scans. After data collection, the results were analyzed. The results showed that 61 percent of the fractures were due to accidents. Among the most common spine damages, 77 percent were related to bone fractures. The highest frequency of brain damages was related to Extradural Hematoma by 23.65 percent. Results of the treatments also showed that $76 \%$ of the patients were partially recovered.
\end{abstract}

\section{Keywords}

Brain Injuries, Neck Injuries, Maxillofacial Fractures 


\section{Introduction}

In the last 20 years, facial bones fractures are common injuries in patients admitted to emergency department of hospitals [1] so that nearly one third of injured patients have some kind of trauma in this area. Prevalence and causes of maxillofacial injuries in different countries are different. In developing countries, the most prevalent cause of maxillofacial injuries is car accidents [1]. Statistics indicates an increase in death toll of traffic accidents in Iran in recent years [2]. In developed countries such as America, damages resulting from trauma (especially vehicle crashes) are the seventh leading cause of death [3]. Several studies conducted around the world show that young pedestrians (children and teenagers) and the elderly are two high risk groups in traffic accidents. Motorcycle riders are another high risk group in traffic accidents [2] [3]. Mokerjy et al. [4] demonstrated in their study that from 714 patients with fractures, traffic accident was the cause of 88 percent of the fractures. Shazia [5] also indicated that in all cases of maxillofacial fractures, the cause was traffic accidents.

Face is one of the most vulnerable parts of the body. At the time of an accident, due to the proximity of vital organs such as the brain and its curtains, the spinal cord, the cervical spinal cord and eyes and also due to physiological problems (controlling airway and breathing), cosmetic and psychological factors can lead to serious complications for patients [3].

The most common facial bones fracture is in the bones of the lower face (Mandible) and the less common one is in upper face. The middle part of the face is in the intermediate state between Mandible and Frontal [6]. The upper and middle part fractures are more severe than lower part fractures and if left untreated, will cause a lot of deformity [6]. Maxillary bone forms most of the middle part. The bone plays a major role in forming the look and the beauty of the person. It also has a major role in the formation of lower lip and orbital bone. Maxillary fractures are of different types. The most common types of these fractures include fractures of Le Fort I, II, III, and fractures of alveolar maxilla and sagittal maxilla [6] [7]. Maxilla fractures are caused by a direct hit from the front or from the side. Today, most of these fractures are caused by traffic accidents. Face and jaws fractures are accompanied with complications such as nasal airway obstruction, the problem in the cranial cavity and Dura rupture, damage to anterior part of the brain, dental occlusion disorder, obstruction of Lacrimal system, abnormalities in appearance, blindness, anophthalmia, diplopia, and loss of sensation in the territory of Infra orbital nerve [8]. Several studies also show that fractures in the facial area have led to the brain and spine cord problems. The study of Grant et al. [9], which conducted in the US, determined that brain damages in people with facial fractures were generally 67 percent. Hugh et al. [10] in a study showed that the incidence of brain damage associated with facial fractures is estimated to be 17.5 percent. Kraos et al. [11] showed that facial fractures are very effective on bran injuries.

With regard to the fact that in many patients with facial fractures it is likely 
not to pay much attention to brain and cervical spine damages and also given the importance of facial fractures and fairly conflicting results of previous studies [12], we decided to investigate the relationship between maxillofacial fractures and brain and neck damages.

\section{Materials and Methods}

In this descriptive-analytical and retrospective study which was conducted as cross-sectional in 2016, a number of 361 people who admitted to the training centers in Rasht with maxillofacial fractures entered the study. Inclusion criteria were: Having fractures of the jaw and face; Full file information. Moreover there were no exclusion criteria. 286 of the sample were male and 75 were female. Majority of the participants in this study (129 people) were between the ages of 21 and 30 . Information collected through questionnaires and patients' records who admitted to Emergency Department of Poursina and Velayat Hospitals with maxillofacial fractures. The patients examined to see whether they have brain and cervical spine injuries. The diagnosis of the fracture and brain and neck injuries had been separately written by the related doctors on the records of the patients based on clinical examination and Plain radiography and CT scans. Cases that were incomplete for various reasons were omitted. Data collected by questionnaires was entered software SPSS for analysis. To describe the data, descriptive tests were used.

Ethical issues were: The information obtained from each person will remain confidential; Any use other than the above design will be prevented; Regarding the retrospective nature of the study and the use of patient files, and the lack of use of the name and personal information of patients, the use of informed consent was not necessary; Avoiding forced entry into the privacy of patients; The confidentiality and unknown presence of subjects in research; Protection of documents; Having specialized knowledge and updated study on the subject of research.

\section{Results}

In this study, 361 patients selected as the study sample. Of these, 286 (79 percent) were men and 75 ( 21 percent) were female. The mean age of patients in this study was $33.5 \pm 19.29$ years with a minimum of 2 and a maximum of 90 years.

The results of the data collection showed that traffic accidents were the most prevalent cause of the fractures in the patients of this study (frequency 219 and 61 percent). Data also showed that the pattern of maxillofacial fractures was as follows: mandibular fractures (frequency 185 and 51 percent) maxillary fractures (frequency 16 and 4 percent), zygomatic fractures (frequency 20 and 6 percent), frontal fractures (frequency 36 and 10 percent), nose fractures (frequency 37 and 10 percent) and compound fractures (frequency 28 and 8 percent). So, the mandible was the most common area of fractures in patients. In all fractured area, fre- 
quency in men was more than women. As for the fracture pattern, there was a significant difference between patients $(p=0.0001)$ as well as between the two sexes (men and women).

In Table 1, the results of the most common injuries of the cervical spine in patients have been discussed.

The most common cervical spine injuries were as follows bone fractures (frequency 7 and 77.8 percent), cervical vertebrae dislocation (frequency 3 and 33.34 percent), disc herniation frequency 1 and (11.12 percent) and spinal cord contusion (frequency 1 and 11.12 percent). Considering the types of cervical spine injuries, there was a statistically significant difference between patients $(p=0.0001)$. In Table 2, the most common brain damages in patients have been discussed.

Among the different types of skull fractures, fractures of the frontal bone were of the highest frequency among patients (frequency 36 and 37.5 percent) which were followed by Ethmoid bone fractures (frequency 31 and 32.29 percent), orbital roof (frequency16 and 16.67 percent) and the sphenoid bone fractures (frequency 13 and 13.54 percent) $(p=0.041)$. Table 3 has discussed the results of treatment (recovery, death, etc.) in the studied patients.

Table 1. The most common cervical spine injuries.

\begin{tabular}{ccc}
\hline Percent & Number & \\
\hline 77.8 & 7 & Bone fracture \\
33.34 & 3 & Cervical vertebra dislocation between 5 and 6 \\
11.12 & 1 & Disc herniation \\
11.12 & 1 & Spinal cord contusion \\
\hline
\end{tabular}

Table 2. The most common brain injuries.

\begin{tabular}{ccc}
\hline Percent & Number & \\
\hline 23.69 & 52 & Extradural hematoma \\
18.89 & 41 & Subdural hematoma \\
12.90 & 28 & Subarachnoid hematoma \\
35.42 & 96 & Skull fracture \\
\hline
\end{tabular}

Table 3. Results of treatment (recovery, death, etc.) in the patients.

\begin{tabular}{ccc}
\hline Percent & Number & \\
\hline 2 & 4 & Transfer \\
11 & 40 & Recovery \\
76 & 275 & Partial recovery \\
7 & 27 & Personal satisfaction \\
4 & 15 & Death \\
100 & 361 & Total
\end{tabular}


The majority of patients (frequency 275 and 76 percent) left the hospital with partial recovery. 11 percent (frequency 40) improved and 7 percent (frequency 27) were discharged with personal satisfaction. 4 percent (frequency 15) of the patients died and 2 percent (frequency 4 ) transferred to other medical centers.

\section{Discussion and Conclusions}

As discussed, trauma is one of the leading causes of death in the communities. Maxillofacial fractures are one of the main problems of traumatic patients. Facial Fractures are likely to associate with complications such as brain and spinal cord damages. With this description, this study aimed to examine the prevalence of brain and cervical damages in patients with maxillofacial fractures. The first finding of the present study was that the most important cause of maxillofacial fractures is car accidents with 61 percent. In most studies in Iran [13] [14] [15], car accidents have also been considered as the most common cause of fractures. Also, similar results were obtained from studies of Patrocinio et al. [16], Adebayo et al. [17], Klenk and Kovacs [18]. In a review article by Oikarinen et al. [19], etiologic differences of maxillofacial fractures in Kuwait, Canada and Finland were compared. The researchers found that traffic accidents were the cause of 55 percent of fractures in Kuwait, 33 percent of fractures in Finland and 7\% in Canada. These results are consistent with information obtained by the Kuwaiti researchers who showed that Eastern countries do not observe the traffic rules. However, the percentage of injuries caused by the conflict in Kuwait is (12\%), Finland (37\%) and Canada (54\%).

The second finding of the present study is that the mandible (51\%) was the most common site of fractures in patients. This finding was consistent with the findings of Akrami Abargouei et al. [20] Kamoliga et al. [21], Maliska et al. [22], Blasilirov and Pasry [23], Karkaovik et al. [24], and it is inconsistent with research of Dongas and Hall [25]. Akrami Abargouei et al. [20] reported that in patients with maxillofacial fractures, the most common site of involvement is the nasal bone (67.4\%) followed by mandible (18.7 percent). In this study, the most common site of involvement is the mandibular condyle (31.47 percent) and the body of the mandible (26.73 percent). Dongas and Hull in their study reached the conclusion that the fracture of the middle third of the face is the most common site of involvement.

The third finding of the study is that the most common injury of the cervical spine of the subjects of this study was the bone fracture (77.8\%) and cervical vertebrae dislocation (33.34\%). The findings of the study were similar to those of Mokerji et al. [4]. In his study, fracture and dislocation of the cervical vertebrae was a total of 63 percent and disc herniation and spinal cord contusion were $37 \%$ among the patients. The researchers also noted that 70 percent of the injuries of the cervical spine have occurred at levels of $\mathrm{C} 1 / \mathrm{C} 2$ or $\mathrm{C} 6 / \mathrm{C} 7$.

The fourth finding of this study is that among various types of skull fractures, frontal bone fracture had the highest frequency in samples of this study (37.5 percent). This is consistent with the findings of Yadave et al. [26]. In the study of Yadave et al. [26], extradural hematoma, subdural hematoma and subarachnoid 
hematoma in patients with maxillofacial fractures were also reported 22, 17 and 14 percent, respectively. In this study, frontal fracture, sphenoid fracture and orbital roof fracture were 21,11 and 14 percent respectively.

Although this study has limitations including lack of generalizability of the results, according to the findings of the study, it can be summarized that the maxillofacial fractures are accompanied with brain and spine cord injuries and this fact was confirmed about the subjects of this study. Traffic accidents were the main cause of maxillofacial fractures in this study. World Health Organization's guidelines on the main factors in preventing accidents are as follows: the use of safety belts, helmets, seats for children, not using of mobile phones while driving and improving the safety of roads. Better design of roads and highways, training courses for drivers and implementation of more serious measures should also be considered. Despite of the preventive laws for mandatory use of safety devices, indices of cooperation in the society affect the performance of these safety solutions.

\section{References}

[1] Lalani, Z. and Bonanthaya, K.M. (1997) Cervical Spine Injury in Maxillofacial Trauma. British Journal of Oral and Maxillofacial Surgery, 35, 243-245. https://doi.org/10.1016/S0266-4356(97)90041-3

[2] Naghavi, M. (2003) Mortality in 18 Provinces of Iran in 1380. Health Deputy. Iran Ministry of Health and medical Education, Tehran, 171-173.

[3] Hoyt, D.B., Coimbra, R. and Potenza, B. (2004) Management of Acute Trauma. In: Townsend, C.M., Beauchamp, R.D., Evers, B.M. and Mattox, K., Eds., Sabiston Textbook of Surgery, 17th Edition, WB Saunders, Philadelphia, 483.

[4] Mukherjee, S., Abhinav, K. and Revington, P.J. (2015) A Review of Cervical Spine Injury Associated with Maxillofacial Trauma at a UK Tertiary Referral Centre. Annals of the Royal College of Surgeons of England, 97, 66-72. https://doi.org/10.1308/003588414X14055925059633

[5] Shazia, Y. (2014) Facial Traumatic among Patients with Head Injuries. Journal of $I M A B$, 20, 535-538. https://doi.org/10.5272/jimab.2014206.535

[6] Lindqvist, C. and Lizuka, T. (1990) Facial Trauma as a Result of Work-Related Accidents. Suom Hammaslaakarilehti, 37, 872-881.

[7] Manson, P.N. (1990) Facial Injuries. In: McCarthy, J.G., Ed., Plastic Surgery, WB Saunders Co., Philadelphia, 867-1141.

[8] Kwon, P.H. and Laskin, D.M. (2000) Clinician's Manual of Oral and Maxillofacial Surgery. 3rd Edition, Quintessence, Chicago, 9.

[9] Grant, A.L., Ranger, A., Young, G.B. and Yazdani, A. (2012) Incidence of Major and Minor Brain Injuries in Facial Fractures. Journal of Craniofacial Surgery, 23, 1324-1328. https://doi.org/10.1097/SCS.0b013e31825e60ae

[10] Haug, R.H., Savage, J.D., Likavec, M.J. and Conforti, P.J. (1992) A Review of 100 Closed Head Injuries Associated with Facial Fractures. Journal of Oral and Maxillofacial Surgery, 50, 218-222. https://doi.org/10.1016/0278-2391(92)90315-Q

[11] Kraus, J.F., Rice, T.M., Peek-Asa, C. and McArthur, D.L. (2003) Facial Trauma and the Risk of Intracranial Injury in Motorcycle Riders. Annals of Emergency Medicine, 41, 18-26. https://doi.org/10.1067/mem.2003.1

[12] Keenan, H.T., Brundage, S.I., Thompson, D.C., Maier, R.V. and Rivara, F.P. (1999) 
Does the Face Protect the Brain? A-Case-Control Study of Traumatic Brain Injury and Facial Fractures. Archives of Surgery, 134, 14-17. https://doi.org/10.1001/archsurg.134.1.14

[13] Ansari, M.H. (2004) Maxillofacial Fractures in Hamedan Province, Iran: A Retrospective Study (1987-2001). Journal of Cranio-Maxillo-Facial Surgery, 32, 28-34. https://doi.org/10.1016/j.jcms.2003.07.010

[14] Motamedi, M.H. (2003) An Assessment of Maxillofacial Fractures: A 5-Year Study of 237 Patients. Journal of Cranio-Maxillo-Facial Surgery, 61, 61-64. https://doi.org/10.1053/joms.2003.50049

[15] Faryabi, J. (2004) Epidemiological Survey of Maxillofacial Injuries in Patients Admitted to Bahonar Hospital of Kerman City during 1996-2002. Journal of the Dental School, 21, 544-551.

[16] Patrocínio, L.G., Patrocínio, J.A., Borba, B.H., Bonatti Bde, S., Pinto, L.F., Vieira, J.V. and Costa, J.M. (2005) Mandibular Fracture: Analysis of 293 Patients Treated in the Hospital of Clinics, Federal University of Uberlândia. Brazilian Journal of Otorhinolaryngology, 71, 560-565. https://doi.org/10.1016/S1808-8694(15)31257-X

[17] Adebayo, E.T., Ajike, O.S. and Adekeye, E.O. (2003) Analysis of the Pattern of Maxillofacial Fractures in Kaduna, Nigeria. British Journal of Cranio-Maxillo-Facial Surgery, 41, 396-400. https://doi.org/10.1016/S0266-4356(03)00165-7

[18] Klenk, G. and Kovacs, A. (2003) Etiology and Patterns of Facial Fractures in the United Arab Emirates. Journal of Cranio-Maxillofacial Surgery, 14, 78-84. https://doi.org/10.1097/00001665-200301000-00014

[19] Oikarinen, K., Schutz, P., Thalib, L., Sándor, G.K., Clokie, C., Meisami, T., et al. (2004) Differences in the Etiology of Mandibular Fractures in Kuwait, Canada, and Finland. Dental Traumatology, 20, 241-245. https://doi.org/10.1111/j.1600-9657.2004.00243.x

[20] Akrami, S., Navab Azam, A. and Akaberi, F. (2014) Epidemiologic Investigation of Maxillofacial Fractures in Admitted Patients in Yazd Trauma Centers (2005-2011). Yazd Journal of Dental Research, 2, 46-60.

[21] Kamulegeya, A., Lakor, F. and Kabenge, K. (2009) Oral Maxillofacial Fractures Seen at a Ugandan Tertiary Hospital: A Six Month Prospective Study. Clinics (Sao Pau1o), 64, 843-848. https://doi.org/10.1590/S1807-59322009000900004

[22] Maliska, M.C., Lima Júnior, S.M. and Gil, J.N. (2009) Analysis of 185 Maxillofacial Fractures in the State of Santa Catarina, Brazil. Brazilian Oral Research, 23, 268-274. https://doi.org/10.1590/S1806-83242009000300008

[23] Brasileiro, B.F. and Passeri, L.A. (2006) Epidemiological Analysis of Maxillofacial Fractures in Brazil: A Five-Year Prospective Study. Oral Surgery, Oral Medicine, Oral Pathology, Oral Radiology, 102, 28-34. https://doi.org/10.1016/j.tripleo.2005.07.023

[24] Chrcanovic, B.R., Freire-Maia, B., Souza, L.N., Arajo, V.O. and Abreu, M.H. (2004) Facial Fractures: A 1-Year Retrospective Study in a Hospital in Belo Horizonte. Brazilian Oral Research, 18, 322-328. https://doi.org/10.1590/S1806-83242004000400009

[25] Dongas, P. and Hall, G.M. (2002) Mandibular Fracture Patterns in Tasmania, Australia. Australian Dental Journal, 47, 131-137. https://doi.org/10.1111/j.1834-7819.2002.tb00316.x

[26] Yadav, S.K., Mandal, B.K., Karn, A. and Sah, A.K. (2012) Maxillofacial Trauma with Head Injuries at a Tertiary Care Hospital in Chitwan, Nepal: Clinical, Medico-Legal, and Critical Care Concerns. Turkish Journal of Medical Sciences, 42, 1505-1512. 